\title{
Saúde e salvação em Paul Tillich, na perspectiva da Teologia da Cultura - o caso da pandemia no Brasil*
}

\author{
Etienne Alfred Higuet ${ }^{* *}$
}

\section{RESUMO}

O texto será organizado segundo o esquema da Teologia Sistemática, da correlação entre situação (questões existenciais) e resposta (interpretação dos símbolos religiosos). Já que a correlação se produz sempre num contexto histórico-cultural, estou usando como referencial os principais conceitos da Teologia da Cultura de Paul Tillich, apresentados na introdução. Em seguida, explicita-se a situação cultural da pandemia no Brasil, centrando-se nas diversas dimensões da cultura da saúde, na situação econômica, nas atitudes negacionistas políticas e religiosas e nas críticas levantadas contra o negacionismo. A segunda parte apresenta algumas reflexões a partir da Teologia da Cultura: a aceitação como resposta ao negacionismo, o pensamento holista aplicado à saúde, o mito e a utopia da saúde universal. A conclusão coloca a questão de um novo Kairos.

Palavras-chave: cultura; saúde; pandemia; negacionismo; pensamento holista; mito.

Health and salvation in Paul Tillich, from the perspective of the Theology of Culture - the case of the pandemic in Brazil

\footnotetext{
Abstract

The text will be organized according to the scheme of Systematic Theology, the correlation between situation (existential questions) and answer (interpretation of religious symbols). Since the correlation is always produced in a historical-cultural context, I am using as a reference the main

* Conferência apresentada no $25^{\circ}$ Seminário em diálogo com o pensamento de Paul Tillich, no dia 20/09/2021.

** Professor aposentado do Programa de Pós-graduação em Ciências da Religião da Universidade Metodista de São Paulo. Presidente da Associação Paul Tillich do Brasil http://orcid.org/0000-0002-3994-6392.
} 
concepts of Paul Tillich's Theology of Culture, presented in the introduction. Next, the cultural situation of the pandemic in Brazil is explained, focusing on the various dimensions of the health culture, the economic situation, the political and religious denialist attitudes, and the criticisms raised against denialism. The second part presents some reflections from the Theology of Culture: acceptance as a response to denialism, holist thinking applied to health, myth and the utopia of universal health. The conclusion raises the question of a new Kairos.

Keywords: Culture; Health; Pandemic; Denialism; Holist Thinking; Myth.

\section{Introdução}

O texto será organizado segundo o esquema da Teologia Sistemática, da correlação entre situação (questões existenciais) e resposta (interpretação dos símbolos religiosos). «A situação que interessa a teologia é a 'totalidade da auto-interpretação humana numa época dada'. Ora essa interpretação da existência se exprime a si mesma nas 'formas científicas e artísticas, econômicas, políticas e éticas' dessa época. ${ }^{1}$ Reconhecemos aqui os diferentes domínios da cultura. [...] As formas culturais atuais expressam a interpretação que o ser humano moderno dá de sua existência. A situação não é um contexto histórico condicionante determinista, mas deve ser entendida no seio da correlação entre o si e o mundo. O método da correlação explica os conteúdos da fé cristã numa interdependência mútua entre as " questões » existenciais e as «respostas » teológicas. As respostas encontradas no evento revelador só serão significativas se tiverem sido correlacionadas às questões que dizem respeito à totalidade da nossa existência e, por esse motivo, se identificam conosco.

Por exemplo, uma situação experimentada « em termos de desintegração, conflito, auto-destruição, falta de sentido e desespero em todas as esferas da vida » encontra a sua expressão em todos os campos da cultura, manifestando as estruturas demônicas trágicas da vida individual e social. Focalizaremos a nossa atenção aqui na cultura da saúde no Brasil. A mensagem deve também ser submetido a interpretação, a qual será uma releitura creativa da tradição, em função da adequação necessária a toda nova situação. É que precisamos ver na correlação,

Paul Tillich, Systematic Theology, op. cit., p. 4. 
em primeiro lugar, uma relação : o divino não pertence a outro mundo que não seja o mundo humano. ${ }^{2}$

Serão usados como referencial alguns dos principais conceitos da Teologia da Cultura ${ }^{3}$ :

1. Visada do incondicionado através das formas condicionadas da cultura (Richtung auf das Unbedingte); a religião é a substância da cultura - a cultura é a forma da religião. Para além do conteúdo excedente de sentido ou sentido incondicional. Que se afirma e se nega, ao mesmo tempo, nas formas condicionadas da cultura.

2. Demônico [mistura de ser essencial e existencial, estruturas que são, ao mesmo tempo, criativas e destrutivas]: "Dämonisch" é "um princípio ambíguo, que contém um elemento criador e um elemento destruidor. É a face obscura do fundamento abissal; é o lado tenebroso do divino, assim como o experimentou Lutero. Poderíamos dizer também que é a perversão do sagrado, o sagrado com um sinal negativo" (GABUS, 1969, p. 5-6). É o elemento abissal do não ser presente na criatura.

3. Autonomia-heteronomia-teonomia: "chamamos de autônoma a cultura empenhada em criar formas de vida pessoal e social sem qualquer referência a algo supremo e incondicional, seguindo apenas as exigências da racionalidade técnica e prática. A cultura heterônoma, por sua vez, submete as formas e as leis do pensamento e da ação ao critério da autoridade da religião eclesiástica e da política quase religiosa, mesmo ao preço de destruir as estruturas da racionalidade. A cultura teônoma expressa nas suas criações a preocupação suprema e o sentido transcendental não como algo que lhe seja estranho, mas como seu próprio fundamento espiritual. "A religião é a substância da cultura e a cultura, a forma da religião". Podemos dizer que esta frase define com precisão o que entendemos por teonomia. Estas distinções possibilitaram a criação da análise teônoma

Ver Id., Ibid., p. 3-8.

3 Remeto ao artigo de Fábio Henrique Abreu, neste mesmo número, para mostrar a organicidade desses conceitos em relação com a filosofia do espírito e do sentido. 
da cultura, da "teologia da cultura" (TILLICH, 1992, p. 85); em função da dialética da teonomia, as expressões culturais do incondicionado e as dimensões da vida são ambíguas.

4. O kairos é o tempo qualitativo, cheio de sentido, de tensões, de possibilidades e de impossibilidades. No Novo Testamento, é o "tempo certo" do advento de Cristo, momento pleno de riqueza, de conteúdo e de significado. Devemos pensar no kairos em termos universais, não o limitando ao passado, mas elevando-o à categoria de princípio geral da história, também relevante para o tempo presente: os momentos de kairos são manifestações extraordinárias do eterno - aceitas, recebidas, reconhecidas - em determinados momentos da história, quando essa se abre ao incondicional (Cf. TILLICH, 1992, p. 64, 73). É a dimensão histórica da irrupção do incondicionado.

5. O princípio protestante (crítico ou profético) que julga toda absolutização de realidade condicionada: O princípio protestante é um princípio universalmente significativo, que se concretizou historicamente no protestantismo, mas que atua em todos os períodos históricos, já que expressa um aspecto da relação divino-humana. Ele contém o protesto divino e humano contra toda pretensão absoluta apresentada por realidades relativas, inclusive as próprias igrejas protestantes. É a concretização da dimensão negativa, de juízo, do incondicionado.

6. A Gestalt de graça é um poder de criar formas novas e superiores (artísticas, litúrgicas, comunitárias, políticas etc.) além da atitude protestante crítica em relação às formas. Embora o princípio protestante rejeite toda identificação da graça com a realidade visível, a Gestalt de graça pode, contudo, ser objeto de uma "intuição imaginativa", como no caso da figura neotestamentária de Jesus enquanto Cristo. A Gestalt de graça é transparente. Ela irradia uma realidade que é mais que ela mesma. Ela pode manifestar-se através de todas as formas seculares ou profanas, com ousadia e risco. Seria o caso, por exemplo, de um sistema de saúde decente no Brasil. (Cf. HIGUET, 2012, p. 90-93) 


\section{A situa)ção}

\subsection{Breve descrição da cultura da saúde no Brasil}

Ao lado da cultura médica, nota-se a persistência e até a recrudescência de uma cultura religiosa da saúde. Em primeiro lugar, a cultura médica. Encontramos dois sistemas assimétricos: o sistema oficial, representado pelo SUS, e o sistema particular. Constata-se uma desigualdade gritante entre as diversas camadas da população, manifestada por dois tipos de medicina: a medicina dos ricos, com o atendimento particular e os planos de saúde (dentro dela, já existe uma grande desigualdade, conforme o tipo do plano e o acesso aos recursos mais modernos da medicina, como os hospitais e laboratórios de ponta, como o Albert Einstein e o Fleury); a medicina dos pobres, com o SUS, caracterizado pela superlotação, longas filas de espera, uma qualidade geralmente inferior, o acesso quase inexistente a certas terapias, como fisioterapia, psicoterapia, odontologia. Porém, grandes progressos foram feitos, na medida da implementação de políticas públicas em todos os níveis, notadamente pelo Sistema Nacional de Imunização.

Mas a insuficiência dessas políticas continua deixando a maioria da população em situação de desamparo. Daí o descrédito da instituição médica e da ciência na qual ela se apoia. Costuma-se suprir a precariedade do atendimento pelo recurso à automedicação, a receitas populares, todo tipo de "simpatia" (comportamento mágico) e práticas de origem religiosa, reconhecidas ou não pelas grandes instituições religiosas.

É preciso também distinguir a medicina científica universitária, reconhecida oficialmente pelo Estado, de medicinas alternativas, como a homeopatia, a acupuntura, a quiropraxia, a psicanálise etc., com a tendência de a medicina oficial incorporar gradativamente determinadas práticas. Contudo, a maioria delas só é acessível à camada mais abastada da população.

A cultura religiosa da saúde comporta práticas usadas muitas vezes paralelamente à medicina científica, às vezes em concorrência com ela. No catolicismo, que ainda é a religião da maioria da população, podemos mencionar: o sacramento da unção dos enfermos, rezas, promessas, romarias, procissões; busca de cura "milagrosa" relacionada com a devoção a Nossa Senhora e aos santos, por meio de santuários, 
imagens, ex-votos. Há santos especializados em determinadas doenças e enfermidades. Há um gradiente entre práticas oficializadas e práticas e rituais considerados supersticiosos pela igreja oficial (exemplo: "castigar" a imagem do santo). Na margem da igreja institucional, encontramos a presença de benzedeiras e curandeiros, assim como práticas e rituais sincréticos entre o catolicismo e a religiosidade indígena ou afro.

As igrejas evangélicas oferecem essencialmente a cura divina, ou cura pela fé, pelo Espírito Santo em nome de Jesus, e os exorcismos, que visam, antes de tudo, as entidades das religiões de matriz africana ou indígena, consideradas como demônios. Do seu lado, as religiões indígenas, afro-brasileiras, espiritismo, budismo, hinduísmo, xamanismo, wicca etc. oferecem diversos métodos para chegar à boa saúde, por exemplo a meditação e ritos de comunhão com a natureza. Em suma, a dimensão religiosa está onipresente na busca da saúde e da cura das enfermidades.

Na perspectiva da Teologia da Cultura, podemos chamar de "demônica" a situação de profunda desigualdade perante a saúde que existe no Brasil.

\subsection{A pandemia no Brasil}

A atualização dos números de casos, de óbitos e da vacinação é feita todo dia pela mídia. Desde o início da pandemia, temos uma taxa de casos, internações e óbitos entre as mais altas do mundo. Estamos num refluxo, mas sofrendo a ameaça de diversas variantes. O que me interessa aqui é mostrar que o modo como a pandemia atingiu o Brasil foi moldado pela cultura da saúde presente no país, manifestando uma exacerbação do seu caráter demônico. ${ }^{4}$

A história da pandemia é marcada pela sobrecarga dos centros de saúde, falta de oxigênio, falta de leitos de UTI, respiradores e remédios para intubação; muitos mortos na fila de espera; sobrecarga dos serviços funerários e cemitérios, enterros noturnos, ausência de toda celebração, muitas vezes ausência dos parentes. Além disso, é grande a desigualdade perante a pandemia, por causa das condições de moradia, da impossibilidade de isolamento, da necessidade de usar os transportes públicos, das fontes de aglomeração como as filas para receber o auxílio

4 Numa situação dinâmica, deixo de levar em conta mudanças e eventos ocorridos após a apresentação da conferência, no dia 20 de setembro de 2021. 
emergencial e a necessidade de trabalho presencial. Há repercussões no tratamento de outras doenças graves, deixado em segundo plano, e consequências na saúde mental, com aumento dos casos de depressão e ansiedade, devidos ao isolamento, à falta de contatos corporais, redução ao mínimo do trabalho de luto, desemprego e dificuldades econômicas.

Por outro lado, a crise econômica atinge todos os setores da economia, especialmente o trabalho informal. Temos $14 \%$ de desempregados, $6 \%$ de desalentados, 27\% sem renda, 122 milhões abaixo do limite de pobreza, 27 milhões passando fome. Houve aumento do número de moradores de rua e alta violenta do preço dos alimentos.

Nessa situação, os auxílios do Estado se revelam decisivos, porém insuficientes, deixando de atender uma parte considerável da população desfavorecida: auxílio emergencial, ajuda às pequenas e médias empresas. Muitos sobrevivem com a assistência social das ONGs, das igrejas, das comunidades (por exemplo, a CUFA, central única das favelas), mas as ajudas diminuem com o tempo. É preciso ressaltar a resiliência do pessoal da saúde, muitas vezes vítima da doença.

Enfim, é preciso mencionar a crise do ensino, sobretudo fundamental e médio, com graves consequências para o futuro de muitos jovens e crianças. $\mathrm{O}$ ensino presencial está voltando nos últimos meses do ano. $\mathrm{O}$ ensino a distância é muito desigual, pelas condições de acesso à internet e as condições econômicas das famílias. Uma das consequências é o aumento da desigualdade entre o ensino particular e o ensino público.

\subsection{O negacionismo e suas consequências}

Em primeiro lugar, observamos atitudes de negação em relação à realidade e gravidade da pandemia (uma "gripezinha"), em relação às medidas de proteção (máscaras, isolamento, distanciamento, ausência de aglomerações), e em relação à necessidade da vacina. Especialmente da parte do presidente da república e daqueles que o apoiam, em particular seus filhos, grupos políticos de extrema direita, empresários, sem esquecer o núcleo duro do governo. Esses grupos agem nas redes sociais, disparando fake News, desacreditando a OMS e a ciência, criticando e sabotando as medidas regionais e locais, desprezando a vacina Coronavac - a única disponível durante um bom tempo - por motivos políticos e ideológicos, recomendando tratamentos inúteis, provocando fricções 
desnecessárias com a China, principal fornecedora de insumos para a vacina, tudo isso a partir da ação de uma espécie de ministério da saúde paralelo e do chamado "gabinete do ódio". As atitudes dos responsáveis políticos estimulam e reforçam o negacionismo já presente naturalmente na população em geral, daí o não respeito das medidas de proteção e as aglomerações em festas, espetáculos, praias, comércio popular etc.

As consequências são severas: despreparo e insuficiência dos serviços de saúde, falta de equipamentos e remédios, falta de testes, atraso na aquisição das vacinas (o que aumentou significativamente o número de casos e de mortes), falta de coordenação nacional das ações contra o vírus, desorganização do ministério da saúde, com casos de corrupção, falta de campanhas de prevenção, subnotificação dos casos e óbitos, falta de proteção às comunidades indígenas.

O negacionismo em matéria de saúde está em correlação com o negacionismo das mudanças climáticas e dos perigos que a deterioração do meio ambiente representa para a vida humana e a vida em geral na terra. A consequência é o não enfrentamento da crise ambiental, em particular do desmatamento da Amazônia e do Cerrado, da grilagem de terras e das queimadas, do garimpo irregular, em razão do enfraquecimento conscientemente provocado dos controles e do afrouxamento das regras (para "deixar a boiada passar"). A crise ambiental no Brasil e no mundo pode ter favorecido o surgimento e a transmissão da pandemia, e constitui um terreno fértil para futuras pandemias.

Em segundo lugar, o negacionismo religioso recebe a sua força de crenças fatalistas e mágicas arraigadas na sociedade brasileira, em particular a ideia de que Deus determina diretamente a hora da morte de todos os seres humanos. Nessas condições, é difícil simplesmente entender o discurso da ciência médica. O negacionismo está presente em certos setores da igreja católica ${ }^{5}$ e do judaísmo, mas, sobretudo, em algumas igrejas evangélicas importantes, especialmente pentecostais e

5 O padre Paulo Ricardo de Azevedo Júnior, representante do catolicismo conservador no canal da renovação carismática ("Canção nova") e nas redes sociais, afirma que a peste - ou a Covid - faz parte da purificação pela qual todos os seres humanos devem passar. É uma das pragas mencionadas pelo Apocalipse. As mortes são produzidas pela mão de Deus e os vivos ou salvos são aqueles que seguem fielmente o seu Senhor. 
neopentecostais, com certo arrefecimento, depois de várias lideranças terem sido atingidas pelo vírus.

Essas igrejas são caracterizadas pela preponderância da autoridade do líder, a teologia da prosperidade, os cultos emocionais e a fé em poderes sobrenaturais e curas milagrosas (Cura divina), daí a resistência contra as orientações médicas, o não respeito das restrições e a ideia de que a vacinação é desnecessária, colocando assim a fé em oposição à ciência, indevidamente "divinizada". A negação está vinculada ao fundamentalismo, a uma fé mágica: confiança cega na cura pelo Espírito-Santo (explicitamente criticada por Tillich, como veremos). Quem crê em Deus ficará livre do vírus, que é uma fantasia criada pela imprensa. A epidemia é obra de Satanás, uma vingança divina a respeito dos pecados da sociedade, especialmente a liberdade sexual e o comunismo, vingança divina que realiza a justiça contra as coisas mundanas. As igrejas criticam o isolamento social e o confinamento, em nome da liberdade do culto, da liberdade de ir e vir e da necessidade do trabalho para fazer funcionar a economia (em particular a economia das igrejas, que vivem de doações).

O bispo Edir Macedo gravou um vídeo dizendo que os fiéis não deveriam se preocupar com o novo coronavírus, que seria inofensivo e uma tática de Satanás. Por via das dúvidas, ele tomou a vacina assim mesmo. O pastor Valdemiro Santiago, dirigente da Igreja Mundial do Poder de Deus, vendia feijão consagrado capaz de curar a Covid 19, mil reais o pacote. A água consagrada por R.R. Soares poderia curar a doença (o missionário não aproveitou o conselho, tendo sido gravemente atingido pela Covid). Segundo o pastor Silas Malafaia, o caos social é pior do que o coronavírus e os jovens poderiam tranquilamente voltar ao trabalho sem medo de serem atingidos, o que foi desmentido pelos especialistas e pelos fatos.

Essas igrejas preconizaram ações de fé como o drive-thru da oração ou da fé e o jejum religioso, para fortificar a fé dos fiéis. Um exemplo é a "Santa convocação do nosso presidente Jair Messias Bolsonaro para um jejum nacional”, no dia 5 de abril de 2021: “A todos os líderes evangélicos do nosso Brasil e seus ministérios respectivos, convocamos a todos para esse jejum nacional em favor da nossa nação". A foto do presidente acompanhava o convite. Contudo, é preciso reconhecer 
que as mesmas igrejas organizam ações de solidariedade em apoio à população vulnerável. Em conclusão, na perspectiva da Teologia da Cultura, encontramos no negacionismo uma heteronomia radical política e, sobretudo, religiosa.

\subsection{A crítica do negacionismo}

Rejeitam o negacionismo: a grande imprensa, a maioria das autoridades estaduais e municipais, a maioria do congresso nacional (com o papel proativo da CPI do Senado), igrejas, inclusive uma minoria ativa de cristãos evangélicos, a ordem dos médicos e a ordem dos(das) enfermeiros(as), a ordem dos advogados, a maior parte do mundo médico e científico, o STF, artistas e intelectuais, sindicatos e partidos políticos. Por exemplo, uma comissão da Ordem dos Advogados do Brasil acusa o presidente de crime contra a humanidade (dia 13 de abril de 2021). As omissões e ações do presidente ao longo da pandemia representam um ataque a um dos pilares da Constituição, que é o direito à saúde e à vida.

No campo religioso, focamos o Conselho nacional de igrejas cristãs (CONIC) e a Conferência Nacional dos bispos do Brasil:

CONIC, 17 de janeiro de 2021

As campanhas negacionistas em torno da pandemia da Covid-19, a falsa oposição entre fé e ciência, com a gradativa perda de empatia e de responsabilidade coletiva, visíveis na resistência ao uso correto de máscara e nas aglomerações contribuíram para que os índices diários de morte e infecção superassem os do início da pandemia. [...] As imagens de Manaus-AM angustiam toda e qualquer pessoa com a capacidade de se colocar no lugar da outra pessoa. Imagens que poderão se repetir em outros estados se não frearmos nossos comportamentos negacionistas e egoístas. A compaixão é um dom de toda e qualquer pessoa, religiosa ou não, capaz de sentir a dor do outro. [...]

Estamos nas mãos de um governo orientado por política de morte. Os números mostram que o argumento utilizado para justificar a não realização de lockdown para conter a pandemia foi falacioso e é um dos principais indicativos da ausência de responsabilidade das pessoas que ocupam postos-chave no país: Executivo, Legislativo e Judiciário. [...] Enquanto pessoas enterram seus familiares, amigos e amigas, assistimos o governo federal anunciando planejamentos inconsistentes para dar início à imunização da sociedade. O sufocamento das pessoas que lutam e lutaram por suas vidas não tem sido suficien- 
te para que as autoridades responsáveis assumam o seu papel. [...] Cada anúncio inconsistente realizado na televisão e nas mídias sociais representa escárnio e desrespeito com a vida da população brasileira. Referência mais precisa

CNBB, 16 de abril de 2021

O Brasil experimenta o aprofundamento de uma grave crise sanitária, econômica, ética, social e política, intensificada pela pandemia, que nos desafia, expondo a desigualdade estrutural enraizada na sociedade brasileira. Embora todos sofram com a pandemia, suas consequências são mais devastadoras na vida dos pobres e fragilizados.

Essa realidade de sofrimento deve encontrar eco no coração dos discípulos de Cristo. Tudo o que promove ou ameaça a vida diz respeito à nossa missão de cristãos. Sempre que assumimos posicionamentos em questões sociais, econômicas e políticas, nós o fazemos por exigência do Evangelho. Não podemos nos calar quando a vida é ameaçada, os direitos desrespeitados, a justiça corrompida e a violência instaurada. São inaceitáveis discursos e atitudes que negam a realidade da pandemia, desprezam as medidas sanitárias e ameaçam o Estado Democrático de Direito. É necessária atenção à ciência, incentivar o uso de máscara, o distanciamento social e garantir a vacinação para todos, o mais breve possível. O auxílio emergencial, digno e pelo tempo que for necessário, é imprescindível para salvar vidas e dinamizar a economia, com especial atenção aos pobres e desempregados. Falta referência precisa

\section{Reflexões na perspectiva da Teologia da Cultura de Paul Tillich.}

\subsection{A aceitação como resposta ao negacionismo}

O negacionismo se recusa, de modo heterônomo, a reconhecer a realidade da pandemia e a amplitude dos riscos que ela representa para os indivíduos e a sociedade. Trata-se de aceitá-la como manifestação do "pecado do mundo" e da alienação do ser humano da sua realidade essencial: o próprio ser, a natureza, o outro, finalmente Deus. Para Tillich, a aceitação é a mais alta expressão da fé: aceitar de ser aceito, apesar de ser inaceitável. É a adesão à irrupção do incondicionado e ao fato de ser possuído por ele. A aceitação diz respeito à negatividade toda da existência, individual e coletiva, inclusive a doença e a morte. Solidão e insegurança, alienação e morte são constantemente superadas na medida em que são voluntariamente aceitas como herança de todas as criaturas. 
Podemos encontrar uma expressão incisiva dessa concepção no sermão de Tillich "Vocês são aceitos" (You are accepted). Vejam a seguir alguns trechos do texto:

Há dois fatos absolutamente decisivos na nossa vida: a abundância do pecado e a superabundância da graça. O pecado não é um ato imoral, $[. .$. é um estado de separação. É uma realidade universal, o destino de toda vida. [...] Sabemos que estamos separados de algo ao qual pertencemos em realidade, e ao qual deveríamos estar unidos. O pecado implica em fatalidade e culpabilidade. Por sua vez, a graça é a unidade da vida. A graça chega "apesar" da separação e da alienação. É a re-união da vida com a vida, a reconciliação de si consigo mesmo. A graça é aceitação do que é rejeitado. A graça transforma a fatalidade num destino que tem sentido; ela transforma a culpabilidade em confiança e coragem. [...] Aquele que é capaz de amar-se a si mesmo é capaz de amar os outros também; aquele que aprendeu a superar o desprezo de si mesmo venceu também o seu desprezo pelos outros.

Às vezes, uma onda luminosa irrompe na nossa escuridão e é como se uma voz nos dissesse: 'Você é aceito. Você é aceito, aceito por aquilo que é maior do que você e do qual você não sabe o nome. Não peça este nome agora; você talvez o encontre mais tarde. Não tente fazer nada agora; talvez mais tarde fará muita coisa. Não procure nada, não realize nada, não projete nada. Aceite simplesmente o fato de ser aceito!' Se isto acontecer conosco, é a experiência da graça. Depois desta experiência, pode ser que não sejamos melhores do que antes, pode ser que não tenhamos mais fé do que antes. Mas tudo é transformado. Neste momento, a graça triunfa frente ao pecado e a reconciliação preenche o fosso da separação. Esta experiência não exige nada, nenhum a priori moral, religioso ou intelectual, apenas a aceitação (TILLICH, 1967, p. 211-222).

No caso da doença, Tillich indica três passos rumo à cura: julgamento, aceitação e transformação. O julgamento é a tomada de consciência da nossa situação de ser ameaçado. Trata-se de assumir a finitude, de nos julgar como finitos e de ajudar os outros a reconhecer sua própria finitude e enfrentar honestamente a realidade da condição humana alienada, sem recorrer à consolação fácil da continuação indefinida da vida após a morte e, no nosso caso, sem contar com uma proteção natural ou sobrenatural contra a doença. Só podemos adotar essa atitude pela força do poder que transcende a finitude, o poder do eterno.

O segundo passo, a aceitação consiste em nos aceitar como aceitos, isto é, salvos, reunidos conosco, com os outros, com a natureza e 
com Deus. A cura e/ou a salvação - que se identificam no pensamento holista de Tillich - não significam a supressão da nossa finitude, mas a sua aceitação. Ela só pode acontecer na base de uma unidade sem ruptura entre o ser humano e o fundamento e telos do seu ser (em linguagem religiosa: Deus). Não se trata de fatalismo, mas de uma aceitação ativa, que significa fazer tudo para superar a doença, até que a morte se torne inevitável. Aceitamos o outro e nós mesmos em nome daquele que nos aceita a todos. Daí resulta a coragem para enfrentar a nossa real situação. A aceitação do outro significa aceitar a angústia dele - isto é, a angústia de uma nação inteira frente à pandemia - sem minimizá-la, sem negá-la, sem recorrer à crença numa cura pela força de uma fé mágica, aliás sem sucesso.

Toda aceitação é paradoxal, apesar de. Só podemos aceitar-nos enquanto aceitos, embora sejamos inaceitáveis aos nossos olhos. É o sentimento de uma alienação trágica, mas também responsável. Todos nós, enquanto cidadãos, devemos considerar-nos como culpados e responsáveis por ter favorecido as condições de transmissão do vírus, e não ter feito tudo em tempo útil para nos defender. É claro que a responsabilidade das autoridades é maior que a dos simples cidadãos. Em vez de reconhecer a sua responsabilidade, certas autoridades usam de todas as desculpas possíveis para decliná-la e fazem tudo para impedir os outros de assumirem a sua responsabilidade.

O ato de aceitação, sendo um ato de reunião ou de amor, é, ao mesmo tempo, transformação: é o terceiro passo da aceitação. Então, na base dessa reunião, as divisões e compulsões da nossa existência separada desaparecem, pela nossa participação, junto com os outros, do poder da Nova Realidade, que é a realidade do amor. A transformação cura ou salvação - só acontece como consequência da aceitação, nunca da obediência nem da imposição (Cf. TILLICH, 1956, p. 121-122).

O Cristo é a expressão simbólica do fato de que Deus nos aceita. Sua cruz manifesta e resolve, ao mesmo tempo, o paradoxo da aceitação (Cf. TILLICH, 1972b, p. 226). Além disso, para que alguém se torne capaz de se aceitar, ele precisa do poder da comunidade, o qual se enraíza no fundamento último, e do poder desse mesmo fundamento. A contribuição de Tillich é decisiva para a avaliação dos diversos procedimentos mais ou menos mágicos da cura divina que encontramos na 
atmosfera religiosa atual. Nesse sentido, Tillich ressalta a importância da saúde religiosa: a religião sadia torna possível para a pessoa e para a sociedade a libertação da escravidão - ou da heteronomia - produzida pelo sistema religioso, sem perder a identidade - ou a autonomia - do centro pessoal e comunitária. Seria a verdadeira religiosidade teônoma, ou ainda uma religiosidade governada pelo princípio protestante (Cf. HIGUET, 2016, p. 129). Podemos interpretar a aceitação, no sentido de Tillich, em termos de teonomia, isto é, de superação da dialética da heteronomia e da autonomia. Para criticar o negacionismo, podemos remeter ao princípio protestante, especialmente no caso das igrejas.

\subsection{O pensamento holista}

O pensamento holista de Tillich a respeito da vida humana, da doença e da saúde pode ser fonte de inspiração para propor respostas adequadas à situação de pandemia e para prevenir futuras situações semelhantes. É que o caráter multidimensional da vida implica na multidimensionalidade da saúde e da doença, logo, também da cura - a qual, para Tillich - se identifica à salvação. É o ser humano integral, individual e coletivo, que deve ser curado. A ambiguidade que atinge uma das dimensões da vida (auto-integração, auto-produção e auto-transcendência) atinge, ao mesmo tempo, todas as outras. A superação das ambiguidades diz também respeito à todas as dimensões da vida, ainda mais no caso do ser humano, que é o ser mais individualizado e mais participante entre todos os seres. Assim, quando a dimensão orgânica está doente, as dimensões psíquica e espiritual sofrem do mesmo modo. A doença, pois, é um sintoma da ambiguidade universal da vida, pois uma tendência auto-destrutiva - ou demônica - está implicada no processo criador da vida (Cf. TILICH, 2005, p. 499).

Para Tillich, a doença ataca, antes de tudo, o sistema de auto-integração do ser humano, sempre ameaçado de desintegração, e a cura deve contemplar as diversas dimensões dessa integração: a dimensão corporal (podemos acrescentar a dimensão ecológica ou ambiental, pois o corpo da terra também está doente), a dimensão psíquica, a dimensão social, e a dimensão do último (ou do Ultimate Concern), que transparece nas outras, por causa da nossa orientação para o incondicionado (Aufrichtung auf das Unbedingte) (Cf. TILLICH, 1972a, p. 209). Falei 
acima na falta de integração das dimensões do ser humano e das ações de luta contra a pandemia dos principais atores econômicos, sociais e políticos no Brasil. Reparei, sobretudo, a falta de integração entre o nacional e o local, e entre o coletivo e o pessoal. É isso que Tillich tem em mente quando menciona a dimensão histórica ou social: "Até que ponto a saúde pessoal é possível numa sociedade que não é uma 'sociedade sadia'?", perguntava Erich Fromm (TILLICH, 1961, p. 172173). É claro que não podemos simplesmente produzir essa sociedade sadia, pois as ambiguidades da existência (os "demonismos") só podem ser superadas fragmentariamente, mas, se não houver saúde nos grupos dirigentes, não haverá saúde social.

A dimensão corporal ou orgânica contém as dimensões física, química e biológica propriamente dita. Em particular, na dimensão química, a saúde é o equilíbrio de substâncias e processos químicos num organismo vivo. Os desequilíbrios são tratados por medicamentos que combatem as doenças e estimulam o organismo, embora a cura total nunca possa ser alcançada. Nesse plano, Tillich condenaria a ausência de interesse pela vacinação e a recomendação de remédios reconhecidos como inúteis e perigosos pelas melhores instâncias médicas. Mas a dimensão química está incluída nas dimensões corporal, psíquica e espiritual. Por isso, é preciso procurar um equilíbrio entre o uso das ciências e das técnicas e as relações humanas. É preciso também que haja colaboração e integração entre os agentes que cuidam das diversas dimensões, como o médico, o psicoterapeuta e o sacerdote (ou o religioso). Nesse sentido, nem a ciência nem a religião podem ter o monopólio da cura, isto é, não pode haver heteronomia de nenhuma das duas (Cf. TILLICH, 1961, p. 168-169).

A ciência médica deve reconhecer seus limites e os científicos devem ficar atentos às outras dimensões humanas. Desse modo, os pacientes não serão tratados como objetos ou como elementos de uma estatística. A medicina deveria também tratar com respeito formas populares tradicionais de tratamento, como o uso de plantas medicinais, mesmo quando recomendado por curandeiros, benzedeiras, pajés ou babalorixás, com o devido discernimento. Do seu lado, a religião deve reconhecer a autonomia da ciência. A colaboração entre os agentes de saúde e os agentes sociais, filosóficos e religiosos indicaria a direção 
de uma teonomia em matéria de saúde. A dialética da autonomia da ciência e da heteronomia da religião pode ser superada - de modo sempre fragmentário - em teonomia. Assim, na perspectiva de uma política nacional ou estadual de saúde, seria importante constituir órgãos consultivos com representantes de todas as instâncias da saúde integral, em cooperação com os níveis econômico, ecológico e político.

Em particular, a questão da saúde psíquica e mental não foi suficientemente considerada pelas autoridades e pela própria medicina. Por exemplo, não foi dada uma atenção adequada ao trabalho de luto e à humanização dos funerais. Nem aos inúmeros casos de depressão que proliferam durante a pandemia.

Os textos de Tillich sobre a angústia poderiam nos inspirar aqui.

A psicoterapia descreveu recentemente a angústia produzida pelo sistema competitivo, pelo isolamento do indivíduo, e pelo superpoder da fatalidade econômica da qual está sujeito. Não há nenhuma dúvida de que esses fatores contribuem ao aumento da angústia em nossa cultura. Mas há raízes mais profundas e mais universais, fundamentalmente uma atitude específica frente à própria existência, uma interpretação especial do ser humano e do sentido da sua vida. É o nível da preocupação suprema, que a religião expressa. Essa preocupação possui aspectos negativos e positivos. Negativamente, é a tomada de consciência da ameaça do não ser na finitude, na culpa e na falta de sentido; positivamente, é a aceitação da palavra que possui um poder último, incondicional, infinito, de resistência ao não ser. Negativamente, é a experiência de uma angústia irrepressível que pode levar ao desespero; positivamente, é a experiência de uma coragem última que assume a angústia e enfrenta a ameaça do não ser (TILLICH, 1950, p. 62).

Segundo Tillich, a angústia existencial, que é consciência da nossa finitude, não pode ser removida, pois é constitutiva do nosso ser. Todavia, a palavra criadora pode mantê-la dentro de certos limites. A angústia pode ser transformada em medo, o qual pode ser enfrentado com coragem. Pois a palavra possui poder, ao introduzir ordem, sentido, definição, objetividade no meio do caos (Tillich se baseia aqui na prática psicanalítica). Mas a palavra é ambígua, demônica, por isso toda agência cultural redutora da angústia pode também produzir angústia. A palavra errada produz destruição na nossa alma e no nosso mundo. Quando a palavra certa (right word) falta, a tentação é de confiar no discurso de 
sistemas religiosos ou políticos de autoridade, por meio de instituições culturais, doutrinas e modos de ação (heteronomia religiosa). É o que acontece atualmente. É que "as famílias, tribos, escolas, exércitos, nações, partidos e movimentos ideológicos, seitas e igrejas podem se tornar neuroses sociais, que protegem contra a angústia numa base discutível, mas apaixonadamente mantida (TILLICH, 1950, p. 59-60)".

A fuga neurótica da realidade pode se expressar sob a forma de fanatismo ou legalismo religioso, ou ainda como angústia imaginária. É na religião que a angústia do não ser e a palavra que enfrenta a angústia alcançam sua plena manifestação. Mas não é sempre o caso das agências religiosas concretas, as igrejas. Muitas vezes, elas oferecem apenas um poder de adaptação ao mundo. Por esse motivo, a mensagem religiosa deixou de ser a palavra certa e segura para a maioria dos seres humanos do Ocidente cristão. Nessa situação, as igrejas produzem também angústia e podem provocar uma fuga no fanatismo religioso, o fundamentalismo e o radicalismo extático (heteronomia e demônico) (Cf. TILLICH, 1950, p. 65). É que, “como realidades humanas, as igrejas são ambíguas: orgulho, auto-elevação, vontade de poder, desejo de auto-realização indevida, descrença ou separação de Deus" (TILLICH, 1956, p. 117).

\subsection{O mito e a utopia da saúde universal}

Os símbolos e mitos de cura e salvação, os relatos de milagres de Jesus, assim como a utopia da vitória sobre a doença como forma de superação da alienação podem ser fontes de inspiração da "palavra certa" na luta contra a doença, com a condição de não ver neles um Deus ex machina (Cf. TILLICH, 1963, p. 192-195). Ao atribuir a desintegração da natureza, da sociedade e do indivíduo a forças demônicas, os mitos nos lembram o sentido da salvação como "cura cósmica", que inclui a natureza (vimos acima que a terra também está doente e necessita de cura), o ser humano como unidade dinâmica e a sociedade. "Em estrita concordância com os mitos da doença cósmica, os mitos de salvação encenam a cura cósmica. A paz é restabelecida na natureza. A saúde corporal é recriada. A vinda do Reino de Deus implica na aparição de um irresistível poder de cura. As doenças corporais (físicas e mentais) e sociais e a própria morte são vencidas" (TILLICH, 1946, p. 19). Desse modo, a função do mito se mantém numa época dominada pela ciência. 
Isso não significa, contudo, que se tenha que ler e compreender o mito literalmente, num sentido fundamentalista ou heterônomo. ${ }^{6}$

A salvação e o poder de cura e de redenção do Novo Ser estavam presentes fragmentariamente em todos os momentos da história, mas em Jesus, o portador do Novo Ser, o poder de redenção se revela de modo ilimitado e completo. Esse poder supera a dicotomia entre o ser humano e Deus, entre o ser humano e o seu mundo, entre o ser humano individual e os outros. Segundo os Evangelhos, as curas de Jesus - sobretudo quando são acompanhadas pela expulsão de demônios - alcançam, ao mesmo tempo, todas as dimensões humanas e a própria natureza. Tillich fala também na força do símbolo ou imagem da Cruz (os símbolos participam da realidade que eles simbolizam): por ser um símbolo da participação de Deus no sofrimento e no pecado do mundo, a cruz de Cristo manifesta e resolve, ao mesmo tempo, o paradoxo da aceitação. Psicologicamente, a visão de fé na cruz produz a experiência do perdão e da redenção do pecado e o sentimento de paz que resulta daí. Por sua vez, o poder do símbolo da ressurreição foi valorizado sobretudo pela igreja ortodoxa, para a qual Cristo é o portador da vida imortal e da luz transcendente que nos ilumina (TILLICH, 1972b, p. 226).

O Novo Ser se manifesta também na presença do Espírito divino ou Presença Espiritual. ${ }^{8} \mathrm{Na}$ função de cura, que age em todas as dimensões reunidas do ser humano, a infusão do Espírito divino se estende a todas as dimensões e funções, antecipando assim o Reino de Deus realizado (ELSÄSSER, 1976, p. 21-22). A presença do poder cósmico de salvação nas pessoas e suas ações, que são signos da Presença Espiritual, não é a suspensão das leis naturais, como afirmaria um supranaturalismo mal compreendido. Tillich observa, contudo, que o poder de cura da Presença Espiritual não coincide com a prática

6 O grito "mito, mito!" dos apoiadores do presidente só pode ser entendido nesse sentido fundamentalista.

7 O retábulo de Issenheim, de Matthias Grünewald, comentado por Tillich, se encontrava numa instituição que abrigava e cuidava de pestiferados, no século XVI, e as imagens da Cruz e da Ressurreição que ele contém deviam ser uma fonte de consolo para os doentes em estado terminal.

8 A expressão "presença espiritual" ressalta a dimensão feminina do divino, que tempera criticamente os excessos do cristomonismo masculino, sustento do patriarcalismo. Temos aqui um fruto da teologia feminista, que inclui o pensamento de Tillich e vai além dele. 
mágica da "Cura pela fé", quando se entende por fé um ato psíquico de concentração ou autossugestão. Há um elemento mágico - isto é, o impacto de um poder inconsciente sobre um outro poder - na maioria das formas de cura, mas esse elemento não se identifica com o poder de cura do ser centrado no universal, isto é, no centro divino. A cura pela fé, no sentido não pervertido do termo, é a recepção da saúde no ato de fé, isto é, a adesão a algo que nos toca incondicionalmente, ao sagrado que não pode ser colocado de força ao nosso serviço. A cura no centro da personalidade, ou a integração das forças contraditórias que escapam do centro e querem se apossar dele, é o resultado desta adesão (TILLICH, 1994, p. 2). ${ }^{9}$

Precisamos distinguir também a oração determinada pelo Espírito da oração mágica. A primeira procura levar o próprio centro pessoal, inclusive a preocupação pela saúde própria ou de outrem, até Deus, e ela está disposta a aceitar a aceitação divina da oração, que o seu conteúdo tenha sido ou não atendido. [...] Uma oração pela saúde, na fé, não é uma tentativa de cura pela fé, mas uma expressão do estado de ser possuído pela Presença Espiritual (TILLICH, 2005, p. 718).

Podemos incluir aqui a valorização relativa das formas religiosas populares de cura (inclusive a "cura divina" do neopentecostalismo)), da cultura popular da saúde, e das práticas de cura de outras religiões e espiritualidades, como as religiões indígenas e de matriz africana, que privilegiam o encontro do sagrado na natureza, ou ainda, como a meditação oriental, o jorei messiânico, a ioga etc., na perspectiva do pluralismo religioso: a Presença Espiritual ultrapassa as fronteiras do cristianismo. Acho que Tillich tenderia a rejeitar um pouco depressa formas supostamente mágicas, talvez por um excesso de racionalismo. Mas ele reconheceria, com certeza, que o poder do mito e do símbolo não se limita ao cristianismo. Nesse sentido, podemos remeter também

9 Uma reportagem da revista Veja, do dia 09/12/2020, ed. 2716, procura mostrar a influência da fé nos tratamentos médicos. Remete a um documento da Sociedade de Cardiologia do Estado de São Paulo, que ressalta a relevância da espiritualidade, da compaixão e do perdão no tratamento de doenças. Segundo estudos internacionais, a frequentação regular da igreja ou templo reduz a mortalidade entre 20 e $30 \%$. A prática religiosa está ligada à secreção de endorfina e dopamina, substâncias do prazer e do bem-estar. Cf. veja.abril. com.br/saúde. 
à dialética do princípio protestante e da Gestalt de graça, na Teologia da Cultura.

O símbolo mitológico do médico universal, aplicado a Jesus (por exemplo, no espiritismo), mostra bem a unidade do campo religioso e do campo médico. A teologia só entrará em conflito com a medicina se ela não entender a salvação como cura, em vez de elevação do indivíduo a um lugar celeste. A medicina só entrará em conflito com a teologia se ela negar o sentido das dimensões não biológicas do ser humano em proveito das dimensões biológica, química e física. Enfim, não há saúde sem a possibilidade essencial da realidade existencial da doença. "A saúde é a doença superada, do mesmo modo que o positivo supera eternamente o negativo. É o sentido mais profundo da medicina (TILLICH, 1961, p. 173)."

Enfim, a utopia da vitória sobre a alienação contém como um dos seus elementos a utopia da cura ou da vitória sobre a doença, em particular sobre as infecções que vêm de fora. Para Tillich, temos aqui uma das grandes forças da história dos povos e da humanidade em geral. Os relatos de cura de Jesus têm como principal função chamar a atenção para o fato de que a utopia esperada, o renascimento do ser e do universo, está prestes a se realizar. A cura faz parte da utopia, e o símbolo do médico ou do curandeiro, daquele que cura ou salva, é um simbólo escatológico de primeira grandeza da teonomia realizada (TILLICH, 1963, p.193).

\section{Conclusão}

A pandemia, um Kairos? O que significaria o Kairos, na situação de pandemia? Parece que houve uma tomada de consciência maior da interdependência da natureza e da cultura, e, em consequência, da necessidade de preservar o meio ambiente em vista da saúde do ser humano, de lutar contra as diversas formas de devastação da natureza e de procurar uma superação das desigualdades na sociedade humana, através de políticas públicas e da prática da solidariedade. Pode-se mencionar um crescimento muito significativo da visibilidade das pessoas e grupos que lutam contra a discriminação racial, sexual e social, ao mostrar que as atitudes que a caracterizam estão enraizadas em racismo estrutural, heterossexismo estrutural, desigualdades sociais estruturais, 
que provocam a miséria e a fome. Em outras palavras, este momento é uma chance para a ecologia integral. Houve tomada de consciência também da necessidade de uma cooperação entre a ciência, a ação social e política e a religião ou espiritualidade, em vista da saúde e da salvação integral dos seres humanos e da vida em geral. Neste sentido, um Kairos pode ser discernido e assumido. Por outro lado, a pandemia pode ter favorecido a exacerbação dos egoísmos, do salve-se quem puder, tanto no plano nacional quanto no plano internacional. Pode ter radicalizado também a esperança demoníaca em um poder autoritário, tanto na política quanto na religião, poder que seria a nossa única salvação na crise atual. Só o futuro nos dirá se o presente Kairos será concretizado positivamente e em que medida. Dependerá do compromisso assumido pelo maior número possível de indivíduos e de grupos.

\section{Referências}

ELSÄSSER, H. Paul Tillich und die Psychoanalyse. In: SCHMIDT, W. Die Bedeutung Paul Tillichs für die kirchliche Praxis. Stuttgart: Evangelisches Verlagswerk, 1976.

GABUS, J-P. Introduction à la théologie de la culture de Paul Tillich. Paris: PUF, 1969.

HIGUET, E. A. Interpretação das imagens na teologia e nas ciências da religião. In: NOGUEIRA, P. A. S. (Org.). Linguagens da religião. Desafios, métodos e conceitos centrais. São Paulo: Paulinas, 2012, p. 69-106.

HIGUET, E. A. Saúde, cura e salvação no pensamento de Paul Tillich. Estudos de Religião, v. 13, n. 16, p. 75-85, 1999.

HIGUET, E. A. Saúde, doença e cura no pensamento de Paul Tillich: reflexões teológicas e pastorais. In: FERNANDES, M. L. (Coord.); ESPERANDIO, M. R. G. \& JUNQUEIRA, S. R. A. (Org.). Espiritualidade, saúde e cultura. A teologia nas fronteiras. Curitiba: Juruá, 2016.

TILLICH, P. Die politische Bedeutung der Utopie im Leben der Völker. In: Der Widerstreit von Raum und Zeit. Schriften zur Geschichtsphilosophie. Gesammelte Werke VI. Stuttgart: Evangelische Verlagswerk, 1963, p. 157-210.

TILLICH, P. A era protestante. São Paulo: Ciências da religião, 1992.

TILLICH, P. Vous êtes acceptés. In: Les fondations sont ébranlées. Paris: Robert Morel, 1967, p. 211-223.

TILliCH, P. Heil und heilen. Dialog, Nova série, nº 18, 1994, p. 2-4. 
TILLICH, P. The relation of religion and health (1946). In: TILLICH, P. The meaning of health: essays in existentialism, psychoanalysis, and religion. Editado por P. Lefevre. Chicago: Exploration Press, 1984. p. 16-51.

TILLICH, P. Anxiety reducing agencies in our culture (1950). In: TILLICH, P. The meaning of health: essays in existentialism, psychoanalysis, and religion. Editado por P. Lefevre. Chicago: Exploration Press, 1984. p. 58-67.

TILLICH, P. Theology and Counseling (1956). In: TILLICH, P. The meaning of health: essays in existentialism, psychoanalysis, and religion. Editado por P. Lefevre. Chicago: Exploration Press, 1984. p. 116-123.

TILLICH, P. The meaning of health (1961). In: TILLICH, P. The meaning of health: essays in existentialism, psychoanalysis, and religion. LEFEVRE, P. (ed.). Chicago: Exploration Press, 1984. p. 165-173.

TILLICH, P. Paul Tillich in conversation on psychology and theology (1972a). In: TILLICH, P. The meaning of health: essays in existentialism, psychoanalysis, and religion. LEFEVRE, P. (Ed.). Chicago: Exploration Press, 1984. p. 203-216.

TILLICH, P. Paul Tillich converses with psychotherapists (1972b). In: TILLICH, P. The meaning of health: essays in existentialism, psychoanalysis, and religion. LEFEVRE, P. (Ed.). Chicago: Exploration Press, 1984. p. 217-249.

TILLICH, P. Teologia sistemática. 5. ed. São Leopoldo: Sinodal, 2005.

\section{Reações à Conferência}

\section{Elton Sadao Tada}

Quando se faz uma leitura da Teologia da Cultura de Paul Tillich, é possível que se utilize dois caminhos. O primeiro é um olhar para o método e para sua aplicação inicial, na sociedade europeia estadunidense do começo do século passado. Outra leitura possível é a da aplicação da Teologia da Cultura para os nossos dias. Em sua conferência, o Professor Etienne Higuet escolheu o segundo caminho, aplicando a Teologia da Cultura no contexto da pandemia da Covid-19 no Brasil. Essa aplicação, revelou uma série de elementos válidos para uma reflexão profunda sobre nossa cultura e abriu a possibilidade de levantamento de outros pontos, o faremos brevemente a seguir.

Primeiramente, o fundamentalismo apresentou-se como uma força de ação bastante presente no contexto da pandemia. Cito como exemplo a guerra pela abertura de igrejas e templos religiosos no pe- 
ríodo de distanciamento social e de quarentena. Como os estados e municípios tinham liberdade para determinar as medidas de fechamento de locais onde as pessoas pudessem se reunir, houve também a determinação do fechamento de locais de culto, dada a grande aglomeração que pode acontecer em tais espaços. Os setores mais fundamentalistas, negando a validade científica do distanciamento social, dominaram o debate que chegou até o supremo tribunal federal, e mesmo lá contaram com uma presença marcante para advogar sobre seus interesses.

Em segundo lugar, penso que a opinião do sujeito de fé que está nas bases da sociedade deve der sido tomada a partir de um embate interno, pois de um lado o sujeito conhecia por meio da mídia os elementos que eram descobertos pela ciência, como a validade do uso de máscaras e o distanciamento social, enquanto de outro lado ouvia de suas lideranças religiosas um discurso negacionista por vezes centrados em promessas de curas mágicas e colocando a fé como fator decisivo sobre a doença. Não é difícil imaginar que boa parte da população tem mais acesso e proximidade dos discursos de seus líderes religiosos do que aos achados da ciência. Por isso, a partir de uma leitura de nossa cultura, podemos pensar na necessidade de uma democratização da ciência, de uma possibilidade de aproximação do que se atinge no cenário científico com o que se vive nas bases da sociedade.

No livro Teologia da Cultura, Tillich fala sobre uma Teologia da educação, na qual ele critica a educação tecnicista e apresenta a necessidade de uma educação que possa humanizar o indivíduo no sentido de proporcionar ao mesmo uma reflexão sobre os sentidos profundos da existência. A saúde em Tillich, como bem apresentado pelo professor Etienne, possui um caráter holístico. É nesse momento que podemos ver um exemplo claro da relação entre a educação e a saúde em nossa cultura. A educação que temos desenvolvidos não humanizou o suficiente para que a população pudesse notar, em tempos de pandemia, nas implicações práticas de suas atitudes para o sentido da coletividade.

Ainda, parece haver um desequilíbrio da tríade amor, poder e justiça na nossa sociedade. Tillich entende que esses três elementos são interligados e que a relação entre os mesmos mantém uma sustentação da vida social. No caso brasileiro, atualmente nota-se que o poder tem sido reiteradamente desenvolvido sem o amor, o que gera um elemento 
tirânico que marca negativamente a vida da sociedade. Isso é o que aconteceu, por exemplo, quando o governo brasileiro se negou a negociar a compra de vacinas, retardando o processo de imunização do povo brasileiro, tendo como consequência mais 600 mil mortes.

Por fim, nota-se a validade e a necessidade de se resgatar a aplicação da Teologia da Cultura. Com ela, pode-se analisar aspectos de uma cultura e apontar seus desarranjos em tom profético, abrindo caminho assim para uma a possibilidade da construção de uma sociedade mais justa.

\section{Resposta}

É muito valiosa a contribuição do Elton Tada. Só posso aceita-la e ressaltar sobretudo a necessidade de praticar a Teologia da Cultura no mundo atual e na nossa situação.

\section{Deborah Vogelsanger}

Prof. Etienne, quando o senhor explicou os conceitos de autonomia, heteronomia e teonomia pude entender que estamos imersos em uma cultura autônoma (ao menos tentamos criar uma cultura deste tipo deste que se instaura um projeto racionalista e cientificista na história) e isto tem afastado a religião das formas culturais de manifestação humana exceto quando ela é um elemento necessário à história a ser contada. Por outro lado, como manifestação cultural natural, a religião nunca deixa de permear o cotidiano humano e as formas culturais a ele associado. As religiões estão aí e as igrejas também, portanto parece-me que há um convívio entre um modo autônomo e um modo heterônomo de cultura e de religião atualmente, embora perceba que talvez falte a presença do sentido do incondicional neste convívio. Essa falta talvez seja um ponto de inflexão entre as manifestações autônomas e heterônomas da cultura e da religião hoje, não sei ao certo, é apenas um pensamento que passou agora pela minha cabeça.

De qualquer modo, o que chama atenção é o conceito de teonomia. Em sua palestra o senhor diz que: A cultura teônoma expressa nas suas criações a preocupação suprema e o sentido transcendental não como algo que lhe seja estranho, mas como seu próprio fundamento espiritual. Bem, esse estado (se posso chamar assim) de espírito em 
que a preocupação suprema e o sentido transcendental sejam inerentes e naturais a nós mostrou-me uma utopia. Um estado a ser alcançado, então haveria um exercício que nos desloca da autonomia para a heteronomia e daí para a teonomia, ou talvez melhor, haja um exercício que una duas partes de nosso espírito - o autônomo e o heterônomo - em direção à teonomia.

Assim, fico com três perguntas a serem feitas ao senhor: 1. Haveria mesmo no conceito de teonomia um sentido utópico subjacente? 2. Quando o senhor fala em dialética da teonomia, estaria se referindo ao movimento que uniria autonomia e heteronomia? 3. O momento teonomo seria possível de fato ou apenas como um estado de espírito que propicia uma cultura de tal tipo? Digo isso por imaginar que, ao cabo, um momento histórico de cultura teonoma poderia eliminar as ambiguidades da vida, eliminado toda a tensão que mantém nossa vida culturalmente produtiva. O que acha?

\section{Resposta}

Para responder sobre a teonomia, é preciso adotar uma perspectiva histórica. Em geral, Tillich tem em mente a passagem para a modernidade no Ocidente. Então, o ponto de partida é a heteronomia, que entra em conflito com a autonomia moderna. $O$ resultado é a absolutização da autonomia, momento no qual Tillich se encontra. Trata-se, então, de superar a autonomia vazia a partir da religião, de modo que a autonomia se supere em cultura teônoma, sem voltar à heteronomia. A cultura teônoma é a cultura autônoma que voltou a tornar-se transparente ao seu sentido último, ao seu conteúdo substancial, ao Ultimate Concern. Podemos aplicar isso à relação entre religião e ciência. A ciência autônoma rejeita a heteronomia religiosa, mas está arriscada a perder o seu sentido profundo, tornando-se puramente instrumental. Ao dialogar com a religião como Ultimate Concern, a ciência pode tornar-se teônoma.

Por outro lado, nenhum dos três momentos da tríade pode se tornar exclusivo. Como você indica, a autonomia racional não chegou a se tornar dominante no Brasil e, como digo no texto do artigo, a religiosidade continua mais presente do que nunca. Por sua vez, o fundamentalismo representa um momento heterônomo que se utiliza do pensamento moderno para criticá-lo. Só podemos falar em tendências, inclusive para a 
teonomia. Parece-me que Tillich conseguiu detectar momentos predominantemente teônomos na história graças a um processo de abstração a partir da diversidade cultural e religiosa sempre presente. Ele afirma também que a teonomia nunca se realiza plenamente na história. Nesse sentido, podemos reconhecer um momento utópico na teonomia, sem, contudo, apagar as diferenças conceituais. Como ideal que indica uma tendência que só pode se concretizar fragmentariamente, a teonomia mostra afinidade com a utopia. A diferença teológica fundamental está no caráter de graça que impregna a teonomia: ela é manifestação do incondicionado num Kairos, quando o eterno se encontra com o temporal. Ela não pode ser produzida, só pode ser recebida. Podemos falar em “estado de espírito", resultado da Presença Espiritual e não de um exercício intelectual. A utopia é apenas uma construção racional projetada na história futura. O seu perigo é de produzir a ilusão de uma possível superação completa das ambiguidades da vida na história humana.

Submetido em: 21-1-2022

Aceito em: 12-02-2022 